\title{
Longitudinal Robust Stability Augmentation for Micro air Vehicle - Design and Validation
}

\author{
Dr. M. Meenakshi ${ }^{1}$ and Prof. M. Seetharama Bhat ${ }^{2}$ \\ 1 Professor, Dept. of Instrumentation Technology, Dr. AIT Bangalore, India \\ Email: meenakshi_mbhat@yahoo.com \\ ${ }^{2}$ Professor, Dept. Of Aerospace Engineering, Indian Institute of Science Banaglore, India \\ Email:msbdcl@aero.iisc.ernet.in
}

\begin{abstract}
This chapter presents a robust fixed order $\mathrm{H}_{2}$ controller designed using Strengthened discrete optimal projection equations (SDOPEs), which approximate the first order necessary optimality condition. Also, the problem of robust performance analysis for a particular robust controller design application is addressed. The novelty of this work is the application of the robust $\mathrm{H}_{2}$ controller to a Micro Aerial Vehicle MAV, named Sarika2 developed in house. The controller is designed in discrete domain for the longitudinal dynamics of Sarika2 in the presence of low frequency atmospheric turbulence (gust) and high frequency sensor noise. The design specification includes simultaneous stabilization, disturbance rejection and noise attenuation over the entire flight envelope of the vehicle. Six degrees of freedom nonlinear equations are linearized, and validated using nonlinear simulation model and is used for the controller design. The resulting controller performance is comprehensively analyzed by means of linear and nonlinear simulation. In addition, robust performance analyses based on LMI techniques are also carried out to strengthen the results. For this, parametric uncertainties due to modeling errors or due to operating point changes have been considered.
\end{abstract}

\section{Introduction}

Ever since mankind's first powered flight was made, research efforts have continuously pushed the envelope to create flying machines that are faster and/or larger than ever before. Now however; there is an effort to design aircraft at the other end of largely unexplored spectrum, where the desire for low cost portable, low-altitude aerial surveillance has driven the development and testing of aircraft that are as small as possible - in other words, on the scale and in the operational range of small birds. Vehicles in this class of small-scale aircraft are known as Micro Air Vehicles or MAVs.

Equipped with small video cameras and transmitters, MAVs have great potential for surveillance and monitoring tasks in areas either too remote or dangerous to send human scouts. Operational MAVs will enable a number of important missions which include 
chemical/radiation spill monitoring, forest-fire reconnaissance, visual monitoring of volcanic activity, surveys of natural disaster areas, and even inexpensive traffic and accident monitoring [1, 2] etc. Additional on-board sensors can further augment MAV mission profiles to include, for example airborne chemical analysis.

In military, one of the primary roles for MAVs will be as small-unit battlefield surveillance agents, where they act as an extended set of eyes in the sky. This use of MAV technology is intended to reduce the risk to military personnel. MAVs can penetrate potential opposite camps and other targets prior to any action against on those targets, which are virtually undetectable from the ground. This significantly raises the chance for overall mission success.

Researchers at the Aerospace Engineering Department at the Indian Institute of Science (I.I.Sc) Bangalore, India have established a long track record in designing, building and testflying (remotely human-piloted) practical MAVs [3-4]. Fig. 1 shows one among few of the recently developed MAVs as well as small UAVs at I.I.Sc. While much progress has been made in the design of ever-smaller MAVs by researchers at I.I.Sc, India and others in the past five years, there is a significant scope for research on autonomous MAV so as to improve their utility to wide array of missions.

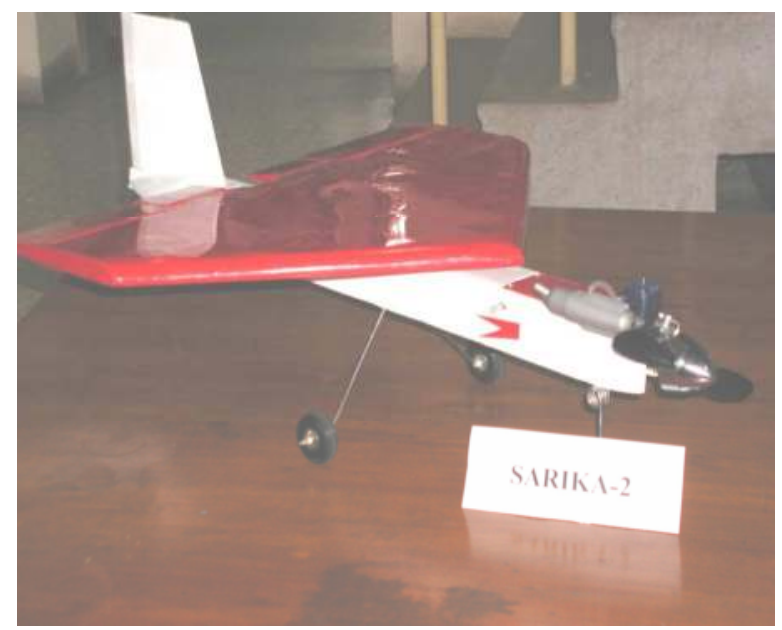

Fig. 1 Micro Air Vehicle: Sarika-2

The first challenging step in achieving such MAV autonomy is the design and development of a robust flight stabilization system because, the uncertainties in the mathematical model associated with the low Reynolds number flight are not fully understood and is high. MAVs have very low moments of inertial property; hence they are highly vulnerable to rapid angular accelerations. Another potential source of instability for MAV is the relative magnitudes of wind gusts, which are much higher at the MAV scale than for larger aircraft [1]. An average wind gust can immediately effect a dramatic change in the flight path of these vehicles. In addition, the pilot may find it difficult to control the aircraft based on visual cues, if its dynamic modes are of high frequency and are lightly damped. Therefore, the problem of controlling an uncertain system such as MAV has been the subject of extensive research in the area of systems and control. 
Generally, a well motivated control goal is to achieve a certain level of performance while controlling an uncertain system. i.e., when designing control system, it is often desirable to obtain guarantees of stability and performance against uncertainty on the physical parameters of the system. Examples of the physical parameters include stiffness, inertia, or viscosity coefficients and aero-dynamical coefficients in flight control. Hence, performance analysis of systems is obviously a very important problem in flight control theory. This problem is also referred to as the robust performance problem. A measure of performance which arises in several situations is given by the $\mathrm{H}_{2}$ norm of a system. For example, in optimal control design, the quadratic performance index of a system can be expressed as the system's $\mathrm{H}_{2}$ norm equivalently [5]. Next, in the design of white noise attenuation, the variance of the output of the system's error caused by white noise can also be represented in the form of $\mathrm{H}_{2}$ norm [6],[7]. In both cases, the purpose of the system design is to select a stabilizing compensator that make the $\mathrm{H}_{2}$ norm of the system as small as possible or less than a given value $\gamma>0$, i.e.,

$$
|| F(s)||_{2}<\gamma
$$

Lower bounds on the achievable $\gamma$ is depends on many constraints like finite bandwidth and non minimum phase zeros of the plant [8]. The design of the compensator is simpler when there are no uncertainties in the system. However, the design process becomes complex when there is uncertainties in the system and hence system becomes a set of family. Generally, in such a case we design a controller for the nominal system first and then check the robust stability and robust performance specifications for the whole system family.

Thus, robust flight controller plays an important role to simplify the task of operating the MAV while enhancing the utility of MAVs for a wide range of missions. Reduced fixed order, robust $\mathrm{H}_{2}$ control is an attractive option among the several robust multivariable methods for controller design, as $\mathrm{H}_{2}$ norm is the more realistic measure of the performance [9]. This allows the direct incorporation of the multivariable robustness measures in to the optimization criterion. Reduced fixed order controller can be synthesized in one step in contrast to the other multivariable robust controller design methods involving two step designs, and hence, guarantees the robustness and stability [10].

Therefore, to deal with the above mentioned challenges in MAV flight control, this chapter proposes the design of digital longitudinal stability augmentation system to improve the handling qualities of Sarika-2 and to achieve satisfactory closed loop disturbance rejection, sensor noise attenuation and robustness specifications [11]. Since Sarika-2 use non inertial quality sensors, and the velocity sensor is not available, a single controller is designed at the central operating point of the vehicle to achieve the desired specifications over the entire flight envelope. Controller is designed using linearized model $[12,13]$ and is validated using nonlinear simulation model of Sarika2, which is developed using simulation software [14]. Next, $\mathrm{H}_{2}$ performance and robustness analysis using LMI techniques is carried out to demonstrate the robustness of the designed system. $\mathrm{H}_{2}$ performance robustness analysis considered here is based on the quadratic Lyapunov function with affine dependence on the uncertain parameters. The resulting tests are less conservative than quadratic stability when the parameters are constant or slowly varying.

The organization of this chapter is as follows. Section 2 briefly explains longitudinal dynamics of Sarika 2 and its verification using nonlinear simulation model. Next section 3 
presents briefly about the controller design methodology. Section 4 briefly explains the $\mathrm{H}_{2}$ performance robustness analysis using LMI techniques. Section 5 describes the simulation results using linear and nonlinear simulation models. Also robust performance analysis results are highlighted in section 5. Finally conclusions are drawn in section 6.

\section{Longitudinal Dynamics of Sarika 2}

Sarika2 (Fig.1) is a remotely piloted small flying vehicle with a wing span of about $0.6 \mathrm{~m}$ and $0.8 \mathrm{~m}$ in length. The vehicle is weighting about $1.75 \mathrm{k} . \mathrm{g}$ at its takeoff. The control surfaces are outboard elevators, inboard ailerons and rudder. The power plant is a 4cc propeller engine with methanol plus castor oil as fuel. Sarika2 can carry a payload comprising video camera, sensors, and transmission systems. Sarika2 has a swept-back delta wing without a horizontal tail. It has a planform area of $0.195 \mathrm{sqm}$, and a constant area square section fuselage of width $0.06 \mathrm{~m}$.

The nonlinear six degrees of freedom equations of the vehicle is given by the following force balance and moment balance equations:

Force Equations

\section{Moment Equations}

$$
\begin{aligned}
& \dot{U}_{1}=R V_{1}-Q W_{1}-g_{0} \sin \theta+\frac{F_{x}}{m} \\
& \dot{V}_{1}=-R U_{1}+P W_{1}+g_{0} \sin \phi \cos \theta+\frac{F_{y}}{m} \\
& \dot{W}_{1}=Q U_{1}-P V_{1}+g_{0} \cos \phi \cos \theta+\frac{F_{z}}{m}
\end{aligned}
$$

$$
\begin{aligned}
& \dot{P}=\left(c_{1} R+c_{2} P\right) Q+c_{3} L+c_{4} N \\
& \dot{Q}=c_{5} P R-c_{6}\left(P^{2}-R^{2}\right)+c_{7} M \\
& \dot{R}=\left(c_{8} P-c_{2} R\right) Q+c_{4} L+c_{9} N
\end{aligned}
$$

where, $\quad c_{1}=\frac{\left(J_{y}-J_{z}\right) J_{z}-J_{x z}^{2}}{J_{x} J_{z}-J_{x z}^{2}} ; \quad c_{2}=\frac{\left(J_{x}-J_{y}+J_{z}\right) J_{x z}}{J_{x} J_{z}-J_{x z}^{2}} ; \quad c_{3}=\frac{J_{z}}{J_{x} J_{z}-J_{x z}^{2}} ; \quad c_{4}=\frac{J_{x z}}{J_{x} J_{z}-J_{x z}^{2}}$ ，

$c_{5}=\frac{J_{z}-J_{x}}{J_{y}}, c_{6}=\frac{J_{x z}}{J_{y}} \quad c_{7}=\frac{1}{J_{y}} ; c_{8}=\frac{J_{x}\left(J_{x}-J_{y}\right)+J_{x z}^{2}}{J_{x} J_{z}-J_{x z}^{2}} ; \quad c_{9}=\frac{J_{x}}{J_{x} J_{z}-J_{x z}^{2}}$

The following two equations (eq. $2 \mathrm{c}$ and $2 \mathrm{~d}$ ) gives the kinematic and navigations equations of the aircraft, which is needed to develop the complete nonlinear simulation model of the aircraft. 


\section{Kinematic equations}

\section{Navigation Equations}

$$
\begin{aligned}
& \dot{\phi}=P+\tan \theta(Q \sin \phi+R \cos \phi) \\
& \dot{\theta}=Q \cos \phi-R \sin \phi \\
& \dot{\psi}=\frac{Q \sin \phi+R \cos \phi}{\cos \theta}
\end{aligned}
$$

$$
\begin{aligned}
\dot{p}_{n}= & U_{1} \cos \theta \cos \psi+V_{1}(-\cos \phi \sin \psi+\sin \phi \sin \theta \cos \psi) \\
& +W_{1}(\sin \phi \sin \psi+\cos \phi \sin \theta \cos \psi) \\
\dot{p}_{e}= & U_{1} \cos \theta \sin \psi+V_{1}(\cos \phi \cos \psi+\sin \phi \sin \theta \sin \psi) \\
& +W_{1}(-\sin \phi \cos \psi+\cos \phi \sin \theta \sin \psi) \\
\dot{h}= & U_{1} \sin \theta-V_{1} \sin \phi \cos \theta-W_{1} \cos \phi \cos \theta
\end{aligned}
$$

For the purpose of controller design, the above set of nonlinear equations is decoupled using small perturbation theory and developed linearized equations, which represents the longitudinal and lateral dynamics of the vehicle. Linearized longitudinal state space equations (Eq. 3) are developed for a straight and level flight, trimmed at six operating points in the speed range of $16-26 \mathrm{~m} / \mathrm{s}$. The state variables are $x=\left[\begin{array}{llll}\Delta u & \alpha & q\end{array}\right]^{\mathrm{T}}$ where $\Delta \mathrm{u}$ is the forward speed $(\mathrm{m} / \mathrm{s}), \alpha$ is the angle of attack (radians), $\mathrm{q}$ (radians/s) is the pitch rate and $\theta$ (radians) is the pitch angle.

$$
\begin{gathered}
\Delta \dot{u}=\left(X_{u}+X_{T u}\right) \Delta u+X_{\alpha}\left(\alpha+\frac{w_{g}}{U_{1}}\right)+\frac{Z_{u}}{U_{1}} q-g\left(\cos \theta_{1}\right) \theta+X_{\delta e} \delta_{e} \\
\dot{\alpha}=\frac{Z_{u}}{U_{1}} \Delta u+\frac{Z_{\alpha}}{U_{1}}\left(\alpha+\frac{w_{g}}{U_{1}}\right)+\left(\frac{Z_{q}}{U_{1}}+1\right) q+\frac{Z_{\delta e}}{U_{1}} \delta_{e} \\
\dot{q}=\left(M_{u}+M_{T u}\right) \Delta u+\left(M_{\alpha}+M_{T \alpha}\right)\left(\alpha+\frac{w_{g}}{U_{1}}\right)+M_{q} q+M_{\delta e} \delta_{e} \\
\dot{\theta}=q
\end{gathered}
$$

where, $\frac{w_{g}}{U_{1}}=\alpha_{g}$ is the angle of attack due to vertical wind gust $\mathrm{w}_{\mathrm{g}}$. The elevator is actuated by electro-mechanical servo systems. The dynamics of the servo actuator measured experimentally, is given by,

$$
\dot{\delta}_{e}=-9.5 \delta_{e}+6.37 u
$$

The measured variables are normal acceleration and pitch rate of the vehicle. The normal acceleration at the centre of gravity c.g. of the vehicle is given by,

$$
a_{z}=U_{1}(\dot{\alpha}-q)
$$

The coefficients of the equations $(3 a-3 d)$, known as aerodynamic stability derivatives are computed using analytical approach $[12,13]$ and are refined using wind tunnel generated 
data [3]. The computed values are again validated using nonlinear simulation model, named FAST [14]. Table 1 shows that the trim values calculated by analytical means match well with those obtained by means of nonlinear simulation. Table 2 gives the steady state coefficients for each trimmed flight condition calculated using the analytical relations. For comparison, Table 2 also lists the corresponding values obtained from nonlinear simulation [14].

\begin{tabular}{|c|l|l|l|l|}
\hline \multirow{2}{*}{$\begin{array}{c}\text { Speed } \\
\mathbf{m} / \mathbf{s}\end{array}$} & \multicolumn{2}{|c|}{$\begin{array}{c}\text { Trim Elevator } \boldsymbol{\delta}_{\mathrm{e}} \text { in } \\
\text { Degrees }\end{array}$} & \multicolumn{2}{c|}{ Trim Alpha $\boldsymbol{\alpha}$ in Degrees } \\
\cline { 2 - 5 } & $\begin{array}{l}\text { Analytical } \\
\text { Approach }\end{array}$ & $\begin{array}{l}\text { Nonlinear } \\
\text { Model }\end{array}$ & $\begin{array}{l}\text { Analytical } \\
\text { Approach }\end{array}$ & $\begin{array}{l}\text { Nonlinear } \\
\text { Model }\end{array}$ \\
\hline 16 & -16.02 & -15.91 & 16.93 & 17.96 \\
\hline 18 & -15.21 & -15.17 & 13.24 & 13.26 \\
\hline 20 & -14.68 & -14.42 & 10.59 & 10.54 \\
\hline 22 & -13.55 & -13.36 & 8.64 & 8.67 \\
\hline 24 & -12.69 & -12.57 & 7.15 & 7.29 \\
\hline 26 & -12.02 & -11.96 & 5.99 & 6.23 \\
\hline
\end{tabular}

Table 1. Trim settings of alpha and elevator

\begin{tabular}{|c|c|c|c|c|}
\hline \multirow[b]{2}{*}{$\begin{array}{c}\text { Speed } \\
\mathrm{m} / \mathrm{s}\end{array}$} & \multicolumn{2}{|c|}{$C_{L 1}$} & \multicolumn{2}{|c|}{$C_{D 1}$} \\
\hline & $\begin{array}{l}\text { Analytical } \\
\text { Approach }\end{array}$ & $\begin{array}{l}\text { Nonlinear } \\
\text { Model }\end{array}$ & $\begin{array}{l}\text { Analytical } \\
\text { Approach }\end{array}$ & $\begin{array}{l}\text { Nonlinear } \\
\text { Model }\end{array}$ \\
\hline 16 & 0.56 & 0.5 & 0.14 & 0.104 \\
\hline 18 & 0.43 & 0.4 & 0.10 & 0.075 \\
\hline 20 & 0.36 & 0.33 & 0.08 & 0.06 \\
\hline 22 & 0.29 & 0.27 & 0.07 & 0.058 \\
\hline 24 & 0.23 & 0.21 & 0.06 & 0.055 \\
\hline 26 & 0.20 & 0.19 & 0.05 & 0.053 \\
\hline
\end{tabular}

Table 2. Trim values and Steady state Coefficients

The continuous state space model is discretized at $50 \mathrm{~Hz}$ (to synchronize with the command PWM input received at the vehicle from radio/pilot command from ground station).The final linearized model used for the controller synthesis includes one sampling period delay to account for computational time requirements. Hence, the final model of the plant consists of six states (four for MAV airframe, one for actuator and one for delay), one control input, wind disturbance input and two sensor outputs from rate gyro and accelerometers.

\section{Fixed order $\mathrm{H}_{2}$ Controller Design}

Fixed reduced order $\mathrm{H}_{2}$ controller is designed to meet the following closed loop specifications. The main requirement of stability augmentation system (SAS) is towards improvement of handling qualities summarized as in S1. In addition, the disturbance rejection and robustness specifications related to the controller design are also summarized in S2, S3 and S4: 
S1: Level - 1-flying qualities of stable airframe dynamics:

Short period damping ratio: $0.35 \leq \xi_{\mathrm{sp}} \leq 1.3$

Phugoid damping ratio: $\xi_{p} \geq 0.5$

S2: Disturbance rejection Specification:

Minimize the sensitivity function below $0 \mathrm{~dB}$ for $\omega<9 \mathrm{rad} / \mathrm{s}$

S3: Sensor noise attenuation Specification:

Obtain $-40 \mathrm{~dB} /$ decade roll off above $\omega=20 \mathrm{rad} / \mathrm{s}$

S4: Robustness Specification:

The controller should be robust to structured and unstructured uncertainty in plant models at all flight conditions. Apart from the above specifications, the closed loop system should also be robust to maximum expected time delays, which may arise due to computational complexity. In addition, the control surface deflection should not exceed its full-scale deflection of \pm 16 degrees.

To meet the above closed loop requirements, robust fixed order $\mathrm{H}_{2}$ controller is designed [11] by considering the performance objective of minimization of $\mathrm{H}_{2}$ norm of the closed loop transfer function $\mathrm{T}_{\mathrm{zw}}$ of the generalized plant given in Fig. 2:

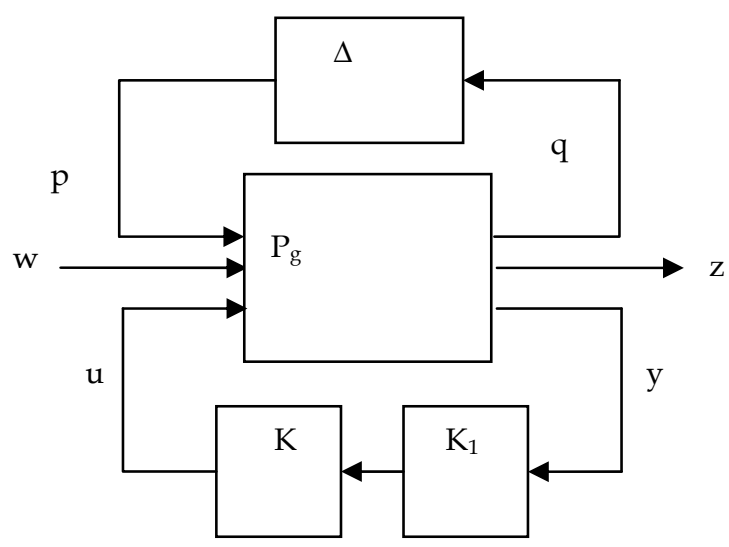

Fig. 2. Standard representation for $\mathrm{H}_{2}$ Design and Analysis

The configuration shown in Fig. 2 contains a generalized plant that is used for robust stability analysis and controller design. The signals ' $w$ ' and ' $z$ ' are exogenous inputs and performance variables respectively. ' $y$ ' is the measured variable, and ' $u$ ' is the control input. $\mathrm{P}_{\mathrm{g}}$ is the generalized plant representing the actual plant and all weighting functions. $\mathrm{K}_{1}$ represents the sensor dynamics including pre-amplifier gains and $\mathrm{K}$ is the controller to be designed. $\Delta$ is the set of all possible uncertainties, grouped in to a single block-diagonal finite dimensional linear time invariant system. The diagram in Fig. 2 is also referred to as a standard LFT formulation with lower linear fractional transformation (LLFT) on K, where $\mathrm{P}_{\mathrm{gK}} \mathrm{K}_{1}$ is the coefficient matrix of the LLFT and upper linear fractional transformation (ULFT) on $\Delta$ where $\mathrm{P}_{\mathrm{g}}$ is the coefficient matrix of the ULFT. LLFT is used in the controller design stage and ULFT is used during the robust performance analysis stage. 
The generalized plant, Fig. 2 can be represented in frequency domain as follows:

$$
\left[\begin{array}{l}
z(z) \\
y(z)
\end{array}\right]=P_{g}(z)\left[\begin{array}{l}
u(z) \\
u(z)
\end{array}\right]=\left[\begin{array}{ll}
P_{g_{11}}(z) & P_{g_{12}}(z) \\
P_{g_{21}}(z) & P_{g_{22}}(z)
\end{array}\right]\left[\begin{array}{l}
u(z) \\
u(z)
\end{array}\right]
$$

where the closed-loop transfer matrix from $\mathrm{w}$ to $\mathrm{z}$ can be given by,

$$
\begin{gathered}
\mathrm{z}=\mathrm{T}_{\mathrm{zw}} \cdot \mathrm{w} \\
\text { and } \mathrm{T}_{\mathrm{zW}}=\mathrm{P}_{\mathrm{g} 11}+\mathrm{P}_{\mathrm{g} 12} \mathrm{~K}_{1} \mathrm{~K}\left(\mathrm{I}-\mathrm{P}_{\mathrm{g} 22} \mathrm{~K}_{1} \mathrm{~K}\right)^{-1}
\end{gathered}
$$

The minimization of the $\mathrm{H}_{2}$ norm of the transfer function from $\mathrm{w}$ to $\mathrm{z}$ i.e., $\mathrm{T}_{\mathrm{zw}}$ over all realizable controllers $\mathrm{K}(\mathrm{z})$ constitutes the $\mathrm{H}_{2}$ control problem. The elements of the generalized plant $\mathrm{P}_{\mathrm{g}}$ are obtained by augmenting the frequency dependent weighting functions and corresponding output vector $\mathrm{z}$ into lower LFT form.

The transfer function, $\mathrm{T}_{\mathrm{zw}}$ between the performance outputs, i.e output sensitivity $\mathrm{S}_{0}$ $\left(S_{o}=\left(I+G K K_{1}\right)^{-1}\right)$ and control sensitivity $\mathrm{S}_{\mathrm{i}} \mathrm{K}$ (with $S_{i}=\left(I+K K_{1} G\right)^{-1}$ ) functions to the disturbance input, $\mathrm{w}$ is given by:

$$
\min \left\|T_{z w}\right\|=\min \left\|\left[\begin{array}{l}
W_{1}(z) S_{0}(z) \\
W_{2}(z) S_{i}(z) K(z)
\end{array}\right]\right\|_{2}
$$

where, $K(z)$ represents the controller transfer function. $W_{1}$ and $W_{2}$ are the weighting matrices used to minimize sensitivity and control sensitivity at low frequency and high frequency region, specified in the design specifications. Reduced fixed order controller, $\mathrm{K}(\mathrm{z})$, defined by:

$$
\begin{gathered}
x_{c}(k+1)=A_{c} x_{c}(k)+B_{c} y(k) \\
u(k)=C_{c} x_{c}(k)+D_{c} y(k)
\end{gathered}
$$

The controller parameters $\left(\mathrm{A}_{c}, \mathrm{~B}_{\mathrm{c}}, \mathrm{C}_{\mathrm{c}}, \mathrm{D}_{\mathrm{c}}\right)$ which minimizes the objective function (Eq.7) are obtained by iteratively solving the set of four coupled modified Riccati and Lyaponv equations known as Strengthened Discrete Optimal Projection Equations (SDOPEs) [15, 11]

\section{4. $\mathrm{H}_{2}$ Performance Robustness Analysis}

Controllers are often designed for a simplified model of the physical plant that does not take into account all sources of uncertainty. Hence a posteriori robustness analysis is necessary to validate the design and obtain guarantees of stability and performance in the face of plant uncertainty. The plant uncertainty occurs due to the imperfect knowledge of the system parameters or because of the alteration of their behavior owing to changes in the operating conditions, aging etc. A feedback compensator is said to achieve robust performance if a 
certain level of closed-loop performance is achieved for all plants in a specified set or for all variations in the plant parameters. On the other hand, stability robustness is achieved if the closed loop remains stable in spite of modeling errors due to high frequency un-modeled dynamics and plant parameter variations. The following subsections explain the representation of the uncertainty and the conditions for robustness of the closed loop system in the face of the uncertainties.

\subsection{Representation of uncertainty}

Robust controller synthesis considers nominal model of the plant along with some assessment of its errors, called model uncertainties. A key assumption in the mathematical models of uncertainty, or errors, is that the uncertain part of the dynamics can be modeled separately from the known part as represented by a nominal model. The mechanism used to represent the uncertainties is called representation of uncertainty.

In robust control literature, the mathematical representation of uncertainties caused by unintentional exclusion of high frequency dynamics, generally take many forms of which the most commonly used is the multiplicative and additive uncertainty model. The additive and multiplicative uncertainties can be mathematically represented as,

$$
\begin{gathered}
\mathrm{G}_{\mathrm{p}}(\mathrm{s})=\mathrm{G}_{\mathrm{p} 0}(\mathrm{~s})+\Delta_{\mathrm{a}}(\mathrm{s}) \\
\mathrm{G}_{\mathrm{p}}(\mathrm{s})=\mathrm{G}_{\mathrm{p} 0}(\mathrm{~s})\left[\mathrm{I}+\Delta_{\mathrm{i}}(\mathrm{s})\right] \\
\mathrm{G}_{\mathrm{p}}(\mathrm{s})=\left[\mathrm{I}+\Delta_{\mathrm{o}}(\mathrm{s})\right] \mathrm{G}_{\mathrm{p} 0}(\mathrm{~s})
\end{gathered}
$$

where, $\Delta_{\mathrm{a}}$ represents an additive perturbation, $\Delta_{\mathrm{i}}$ an input multiplicative perturbation and $\Delta_{\mathrm{o}}$ an output multiplicative perturbation. $\mathrm{G}_{\mathrm{p} 0}(\mathrm{~s})$ is a nominal plant transfer function, which is a best estimate, in some sense, of the true plant behavior, and $G_{p}(s)$ denote the true transfer function of the plant.

In general, uncertainties are represented in two forms. i.e, uncertain state space model, which is relevant for systems described by dynamical equations with uncertain and/or time-varying coefficients and linear fractional representation where the uncertain system is described as an interconnection of known LTI systems with uncertain components called uncertain blocks. Each uncertain block $\Delta_{\mathrm{i}}($.$) represents a family of systems of which only a$ few characteristics are known.

\subsubsection{Uncertain state space model}

Physical models of a system often lead to a state space description of its dynamical behavior. The resulting state space equations typically involve physical parameters whose value is only approximately known, as well as approximations of complex and possibly nonlinear phenomena. In other words, the system is described by an uncertain state space model,

$$
\begin{aligned}
& E \dot{x}=A x+B u \\
& y=C x+D u
\end{aligned}
$$


where the state space matrices A, B,C, D, E ( $\mathrm{E}$ is nonsingular) depend on uncertain and/or time-varying parameters or vary in some bounded sets of space of matrices. Generally, these uncertain models are grouped in to two categories: i) Polytopic Models. ii) Affine Parameter dependent Models.

\section{i) Polytopic models}

A linear time varying system represented by,

$$
\begin{gathered}
E(t) \dot{x}=A(t) x+B(t) u \\
y=C(t) x+D(t) u
\end{gathered}
$$

whose system matrix,

$$
S(t)=\left[\begin{array}{cc}
A(t)+j E(t) & B(t) \\
C(t) & D(t)
\end{array}\right]
$$

varies within a fixed polytope of matrices, i.e.,

$S(t) \in \operatorname{Co}\left\{S_{1}, S_{2} \cdots S_{k}\right\}:=\left\{\sum_{i=1}^{k} \alpha_{i} S_{i}: \alpha_{i} \geq 0, \sum_{i=1}^{k} \alpha_{i}=1\right\}$ where, $S_{1}, S_{2} \cdots \cdots S_{k}$ are

given vertex systems: $S_{1}=\left[\begin{array}{cc}A_{1}+j E_{1} & B_{1} \\ C_{1} & D_{1}\end{array}\right] \cdots \cdots \cdots \cdots S_{k}=\left[\begin{array}{cc}A_{k}+j E_{k} & B_{k} \\ C_{k} & D_{k}\end{array}\right]$ is

called a polytopic systems. $S(t)$ is a convex combination of the system matrices $S_{1}, \ldots \ldots . S_{k}$. The nonnegative numbers $\alpha_{1} \cdots \cdots \cdots \alpha_{k}$ are called the polytopic coordinates of $\mathrm{S}$. These models also arises when the state space models depends affinely on time varying parameters.

\section{ii). Affine parameter dependent models}

When the equation of physics involves uncertain or time varying coefficients, the linear systems give rise to parameter dependent models (PDS) of the form,

$$
\begin{gathered}
E(\theta) \dot{x}=A(\theta) x+B(\theta) u \\
y=C(\theta) x+D(\theta) u
\end{gathered}
$$

where $\mathrm{A}(),. \mathrm{B}(),. \mathrm{C}(),. \mathrm{D}($.$) and \mathrm{E}($.$) are known functions of some parameter vector, \Theta=\left(\theta_{1}\right.$, $\left.\theta_{2}, \ldots \theta_{\mathrm{n}}\right)$. The state matrix $\mathrm{A}(\theta)$ depends affinely on the parameters $\theta_{\mathrm{i}}$ That is,

$$
\begin{aligned}
& A(\theta)=A_{0}+\theta_{1} A_{1}+\cdots \cdots \cdots \theta_{K} A_{K} \\
& B(\theta)=B_{0}+\theta_{1} B_{1}+\cdots \cdots \cdots \theta_{n} B_{n}
\end{aligned}
$$

and so on where $A_{0}, A_{1} \ldots A_{k} B_{0}, B_{1} \ldots B_{k}$ are known fixed matrices. Affine parameter dependent models are well suited for Lyapunov based analysis and synthesis and are easily converted to linear fractional uncertainty models for small gain based design. 


\subsubsection{Linear fractional models of uncertainty}

This is the more general form of uncertainty representation of the system's dynamical and parametric uncertainty. A standard Linear fractional form used for robustness analysis is depicted in Fig. 3 consisting of a nominal map Gp and a perturbation $\Delta$ that enters the system in feedback fashion. The overall uncertain system will be denoted by $(\mathrm{Gp}, \Delta)$. Gp is assumed to be finite dimensional, linear time invariant (LTI) stable system. Gp(s) includes all known LTI components like controller, nominal models of the system, sensor and actuators. The input $\mathrm{u}$ includes all external, actions on the system and output y consists of all output signals generated by the system. $\Delta$ is a structured description of the uncertainty. Generally $\Delta$ is represented in block diagonal form, $\Delta=\left(\Delta_{1} \ldots \Delta_{\mathrm{k}}\right)$ where each uncertainty block $\Delta_{\mathrm{i}}$ accounts for one particular source of uncertainty like, neglected dynamics, nonlinearity, uncertain parameter etc. In each case of $\Delta$, there is a restricted class $\Delta$ of allowed perturbations, which are usually assumed normalized to the ball of uncertainty: $\mathrm{B}_{\Delta}$ $=\{\Delta \in \Delta:|| \Delta|| \leq 1\}$ in some operator norm.

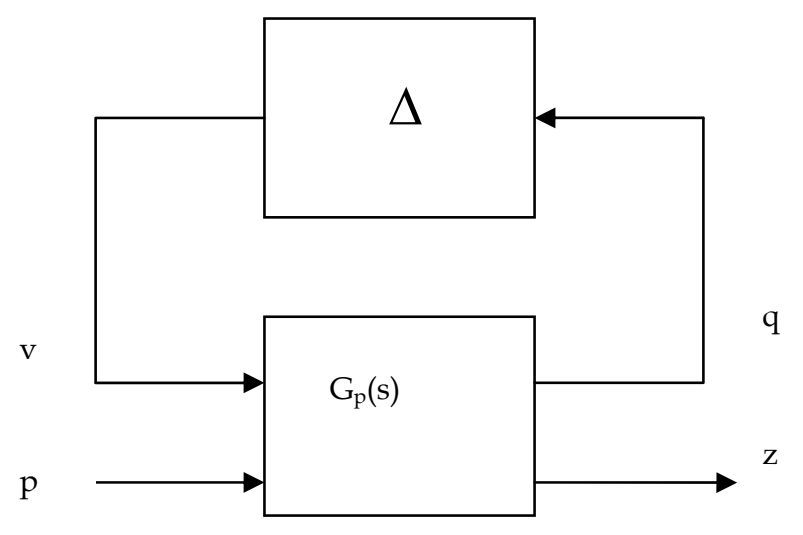

Fig. 3 LFT Formulation for Robust Analysis

\subsection{LFT Formulation for Robust Analysis Quantification of Parameter Uncertainty:}

Consider a linear time-invariant (closed loop) system $\sum(\theta)=(A(\theta), B(\theta), C(\theta)$ ), where $\theta \in \Theta$ is a vector of real uncertain parameters. Let $F(\theta)$ denote the square of the $\mathrm{H}_{2}$ norm of $\sum(\theta)$. The main problem is to compute the supremum of $F(\theta)$ as $\theta$ ranges in $\Theta$. This is a rather difficult performance robustness analysis problem. One among the different methods of robust performance analysis, consists of the uncertain linear systems that can be described by state space equations of the form given in Eqs (15-17), where $A_{0}, A_{1} \ldots A_{K}$ are known fixed matrices. It is also assumed that the lower and upper bounds of the parameter values and its rate variations is known. i.e,

1. Each parameter $\theta_{\mathrm{i}}$ ranges between known external values $\underline{\theta}_{i}$ and $\bar{\theta}_{\mathrm{i}}$ :

$$
\theta_{i} \in\left[\underline{\theta}_{i} \bar{\theta}_{i}\right]
$$

2. The rate of variation $\dot{\theta}_{i}$ is well defined at all times and satisfies: 


$$
\dot{\theta}_{i} \in\left[\underline{v}_{i} \bar{v}_{i}\right]
$$

where $\underline{v}_{i} \leq 0 \leq \bar{v}_{i}$ are known as lower and upper bounds on $\dot{\theta}_{i}$.

The first assumption means that the parameter vector $\theta$ is valued in any hyper- rectangle called parameter box. In the sequel,

$$
v:=\left\{\left(w_{1}, \cdots, w_{K}\right): w_{i} \in\left\{\underline{\theta}_{i}, \bar{\theta}_{i}\right\}\right\}
$$

denotes the set of the $2^{\mathrm{K}}$ vertices or corners of this parameter box. Similarly equation defines an hyper-rectangle of $\mathrm{R}^{\mathrm{K}}$ with corners in

$$
\mathfrak{R}:=\left\{\left(\tau_{1} \cdots \tau_{K}\right): \tau_{i} \in\left\{\underline{v}_{i}, \bar{v}_{i}\right\}\right\} .
$$

Note that 2) allows for more accurate modeling of the rate of variation than a mere bound on $\left|\dot{\theta}_{i}\right|$. Also equation - encompasses time invariant parameters as the special case $\underline{v}_{i}=\bar{v}={ }_{i} 0$. Though this model is somewhat restrictive, still it covers many relevant uncertain systems.

It is essential to distinguish between time in variant and time varying parameters. Time invariant uncertain parameters have a fixed value that is known only approximately. In this case the state equation is time invariant. In the case of time varying uncertain parameters, the parameter values vary in the range $\left[\begin{array}{ll}\theta_{i} & \bar{\theta}_{i}\end{array}\right]$ during the operation. The system is then time varying.

Generally, to accesses the robust performance, of the closed loop system, parametric uncertainty within the control bandwidth in the form of errors in frequency and model damping can be introduced.

\subsubsection{Robust Stability}

For an affine parameter dependent system given in Eq. 15, if a positive definite Lyapunov functions of the form,

$$
\begin{gathered}
V(x, \theta)=x^{t} Q(\theta)^{-1} x \\
\text { where, } Q(\theta)=Q_{0}+\theta_{1} Q_{1}+\cdots \cdots \theta_{n} Q_{n}
\end{gathered}
$$

is exists, then the system is robustly stable. $[7,8]$

\subsubsection{Quadratic stability}

A system, Eqn. 15, is said to be quadratically stable if there exists a positive-definite quadratic Lyapunov function $\mathrm{V}(\zeta)=\zeta \mathrm{TP} \zeta$ that decreases along every trajectory of the system. $[7,8]$ 


\section{Results and Analysis}

Suitable weighing matrices are selected by trial and error method and minimum order controller is designed to meet the design specifications. It is found that a third order controller is sufficient to meet the closed loop requirements. The two elements of transfer function matrix of the third order controller $\mathrm{K}_{1 \times 2}$ is given by,

$$
K(z)=\frac{1}{\Delta}\left[0.0019(z-0.1614)(z-0.9904) \quad 0.036\left(z^{2}-2.005 z+1.008\right)\right]
$$

where, $\Delta=(z-0.3828)(z-0.9397)(z-0.9875)$.

With this controller, at all flight conditions, short period and phugoid damping remains greater than 0.35 and 0.5 respectively, hence, the stringent level-one flying quality requirement is met.

\subsection{Nonlinear simulation results}

In practice, it is very difficult to fly the model continuously at constant altitude and to initiate control action from an equilibrium condition as assumed while designing the controller. The variation in altitude in real flight can give rise to variations in density, which in turn can affect the dynamics of the aircraft. Also, the effect of the coupling of longitudinal and lateral dynamics can play a major role on the aircraft performance. In order to assess the performance of the controller in the presence of such uncertainties, full scale closed loop nonlinear simulation with both longitudinal controller is presented in this section. The nonlinear program used for this purpose is the FAST package developed by NAL, Bangalore [14]. FAST is only an open loop simulation software package for the given aircraft. In order to simulate the closed loop response of Sarika-2, at first the input file is formulated in the standard format [14]. In order to simplify the controller implementation procedure in real time, controller is placed in the feedback path, in contrast to the cascade configuration used while designing the controller. This is because, in feedback configuration, initial conditions for controller can safely be set to zero.

In order to assess the performance of the controller, two different conditions are considered. First the aircraft is trimmed for different cruise speeds at constant altitude and the closed loop response to doublet input is simulated. Next, the aircraft is trimmed at different altitudes and closed loop response to doublet input is simulated.

\subsubsection{Closed loop Response due to variation in Cruise Speed}

The closed loop nonlinear responses are simulated at 3 different nominal flight speeds, (16 $\mathrm{m} / \mathrm{s}, 20 \mathrm{~m} / \mathrm{s}$ and $26 \mathrm{~m} / \mathrm{s}$ ) at constant altitude. After the aircraft is trimmed for straight and level flight, the simulation is started at $\mathrm{t}=0$ with a doublet input along the pitch axis. i.e., a positive $0.1 \mathrm{~ms}$ input is applied at $\mathrm{t}=0$ and held it for $2 \mathrm{~s}$. Next, a $-0.1 \mathrm{~ms}$. input is applied and is zeroed after 2 s. The closed loop responses obtained from nonlinear simulation models, at different flight conditions, are given in Figs. $4-6$. 

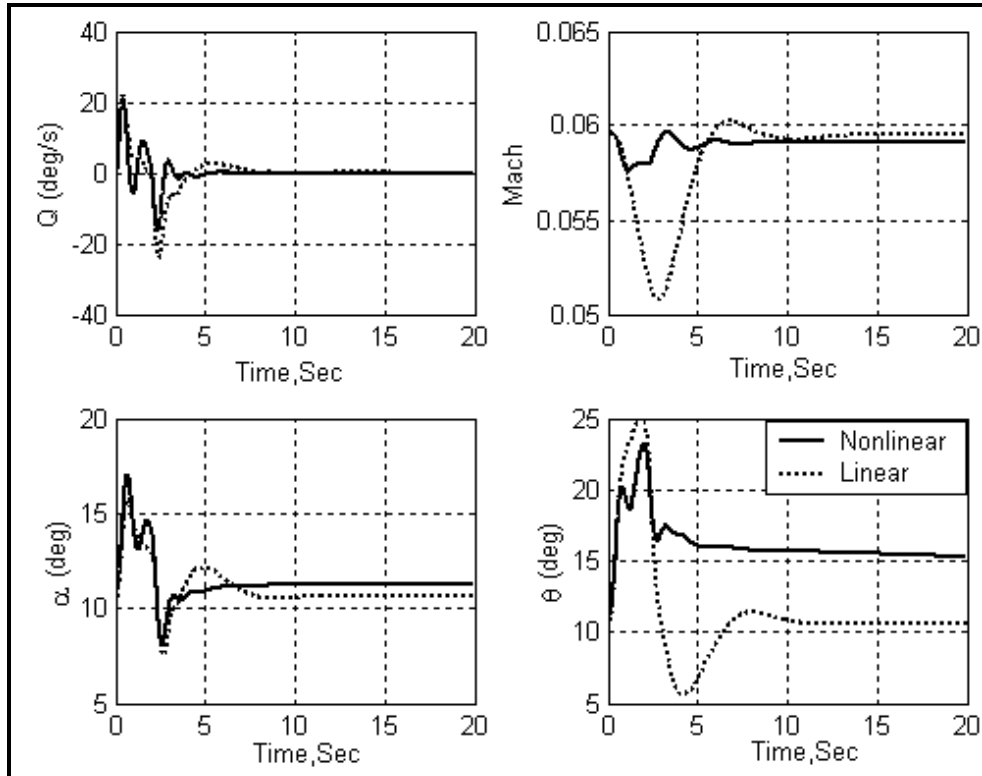

Fig. 4a Closed Loop Responses from Nonlinear and Linear Models at 20m/s
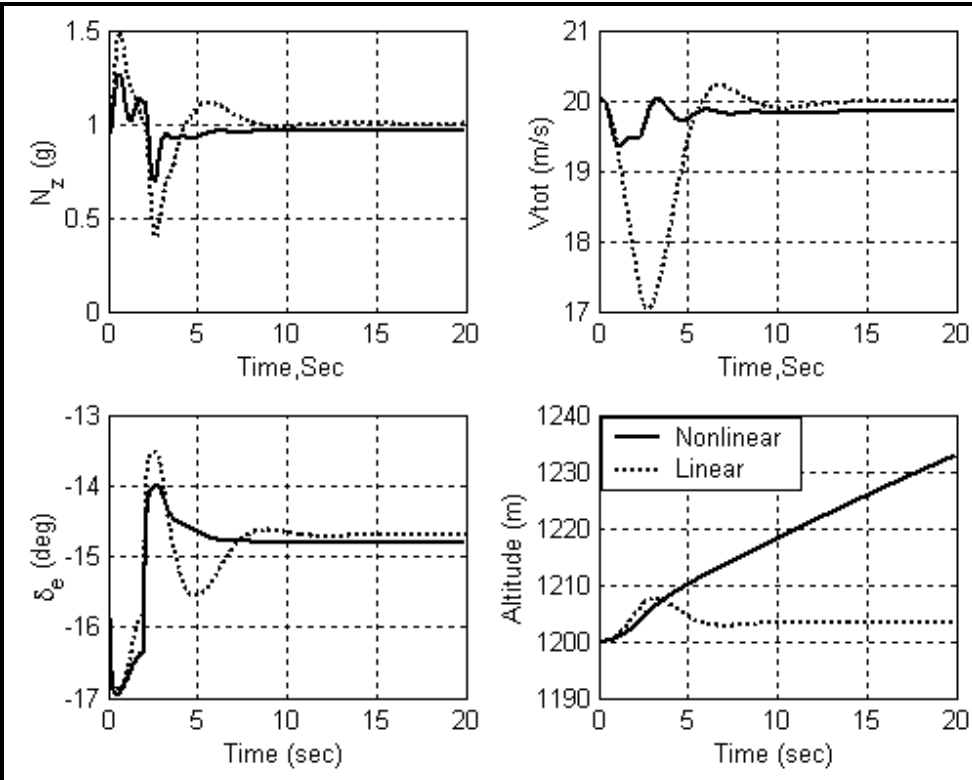

Fig. 4b Closed Loop Responses from Nonlinear and Linear Models at 20m/s 


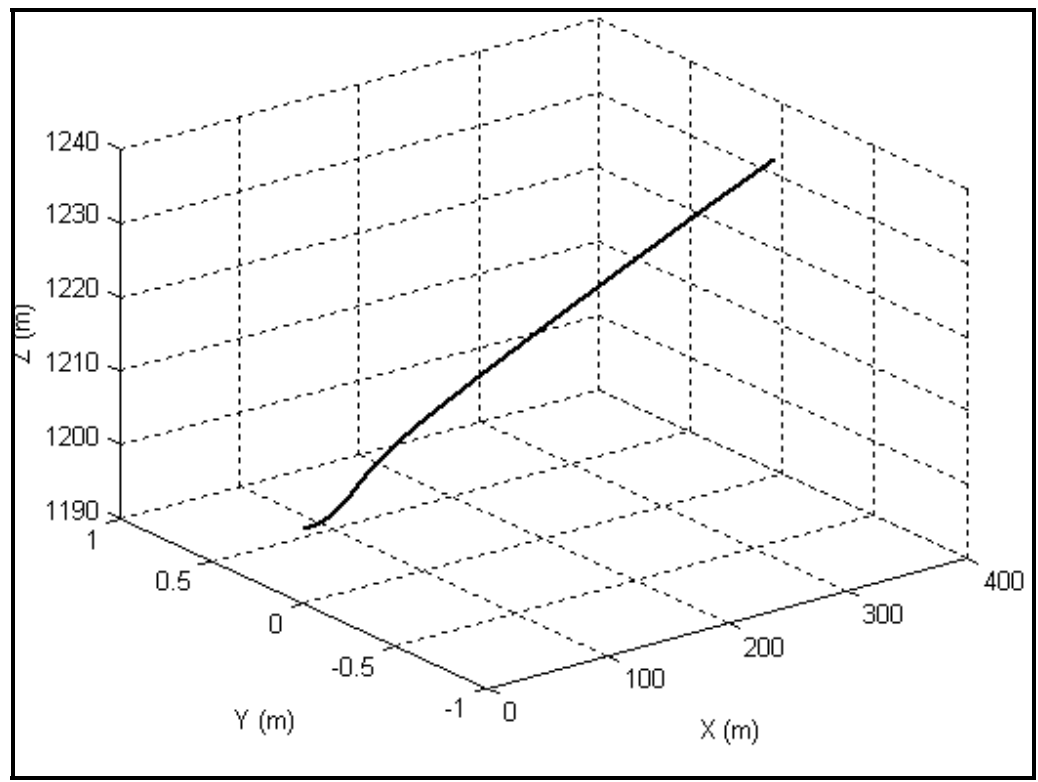

Fig. 4c Closed Loop Responses from Nonlinear and Linear Models at 20m/s
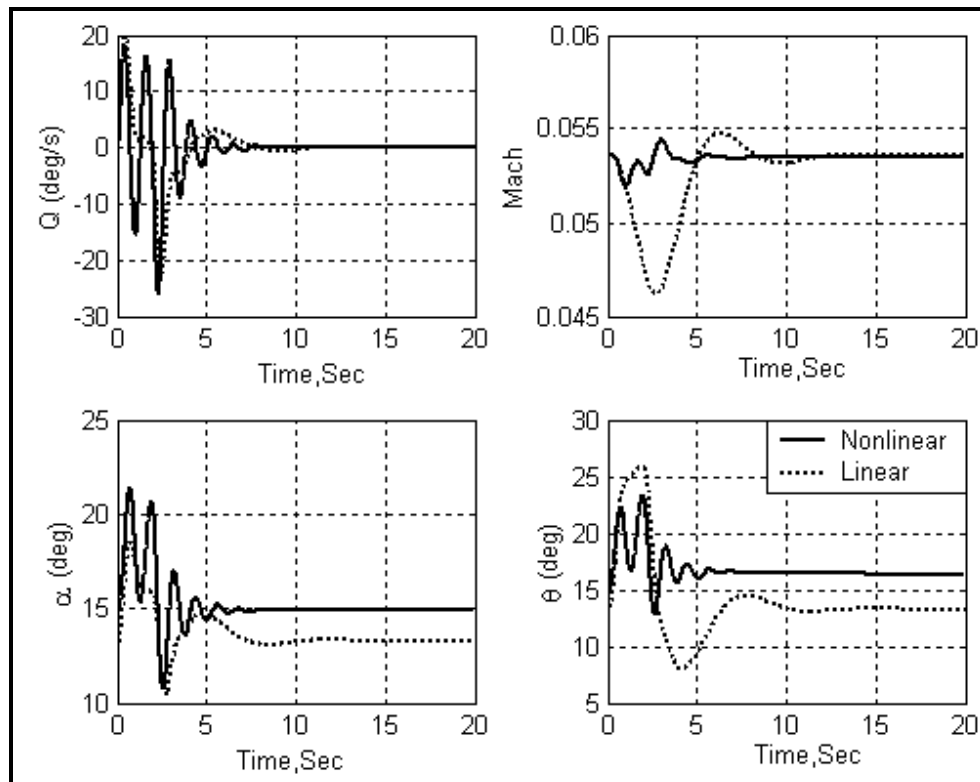

Fig. 5a Closed Loop Responses from Nonlinear and Linear Models at 16m/s 


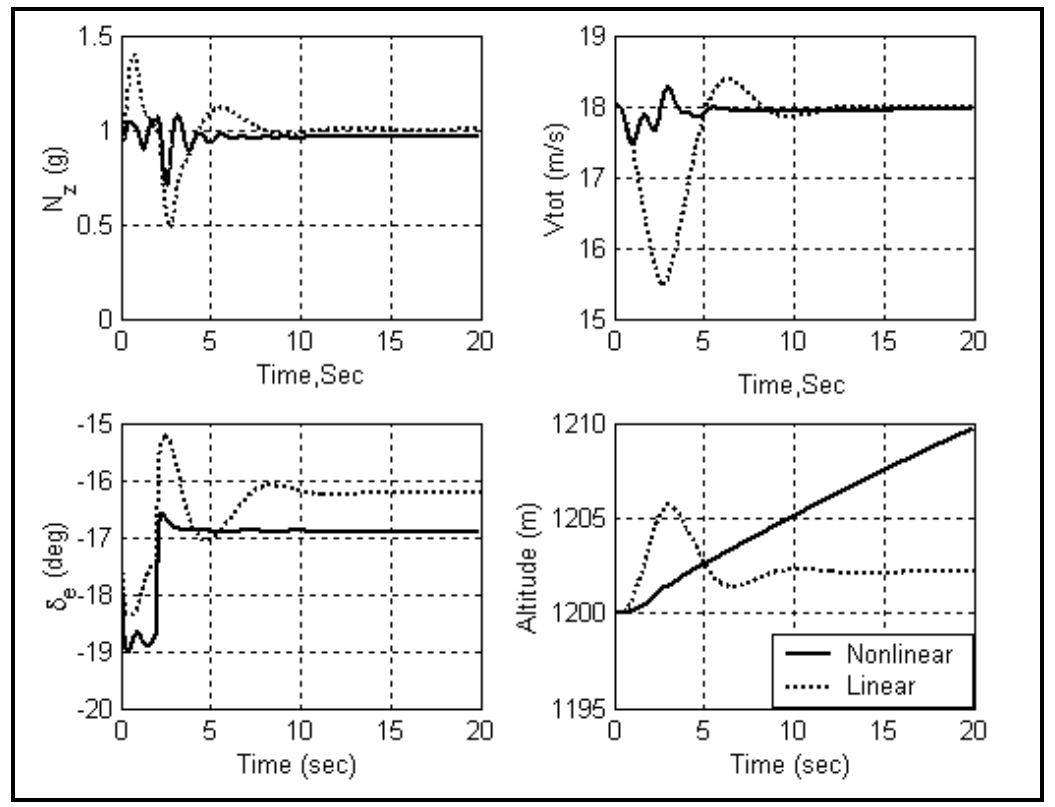

Fig. 5b Closed Loop Responses from Nonlinear and Linear Models at 16m/s

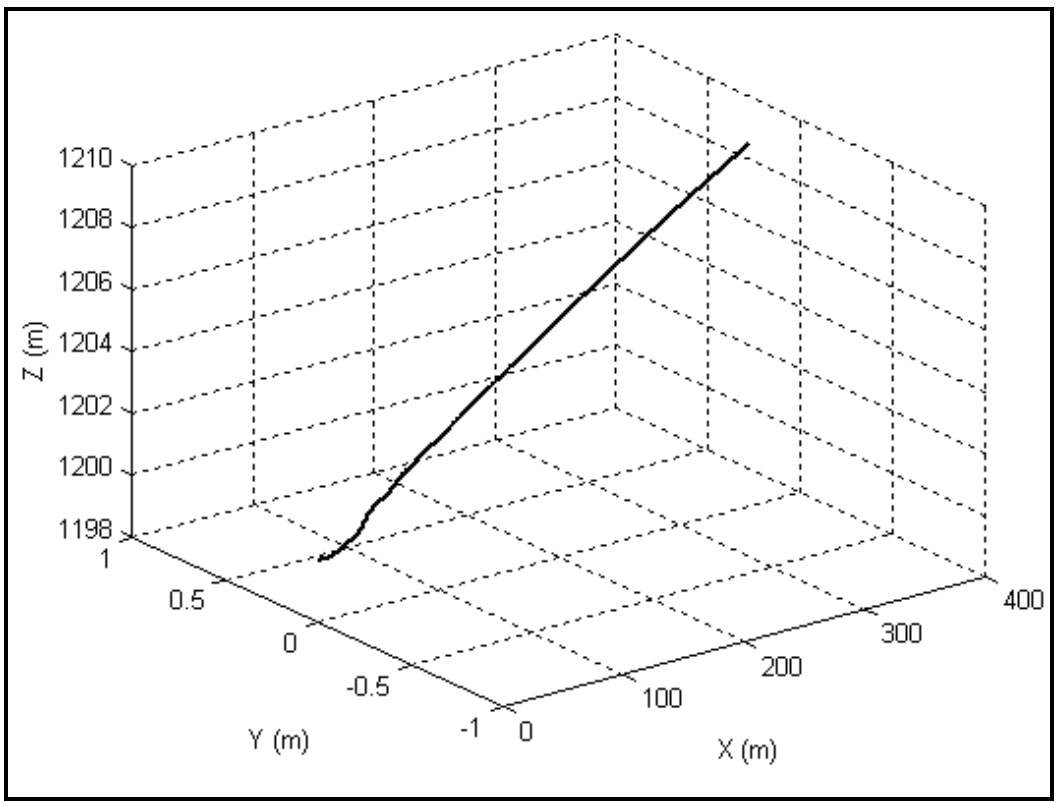

Fig. 5c Closed Loop Responses from Nonlinear and Linear Models at 16m/s 


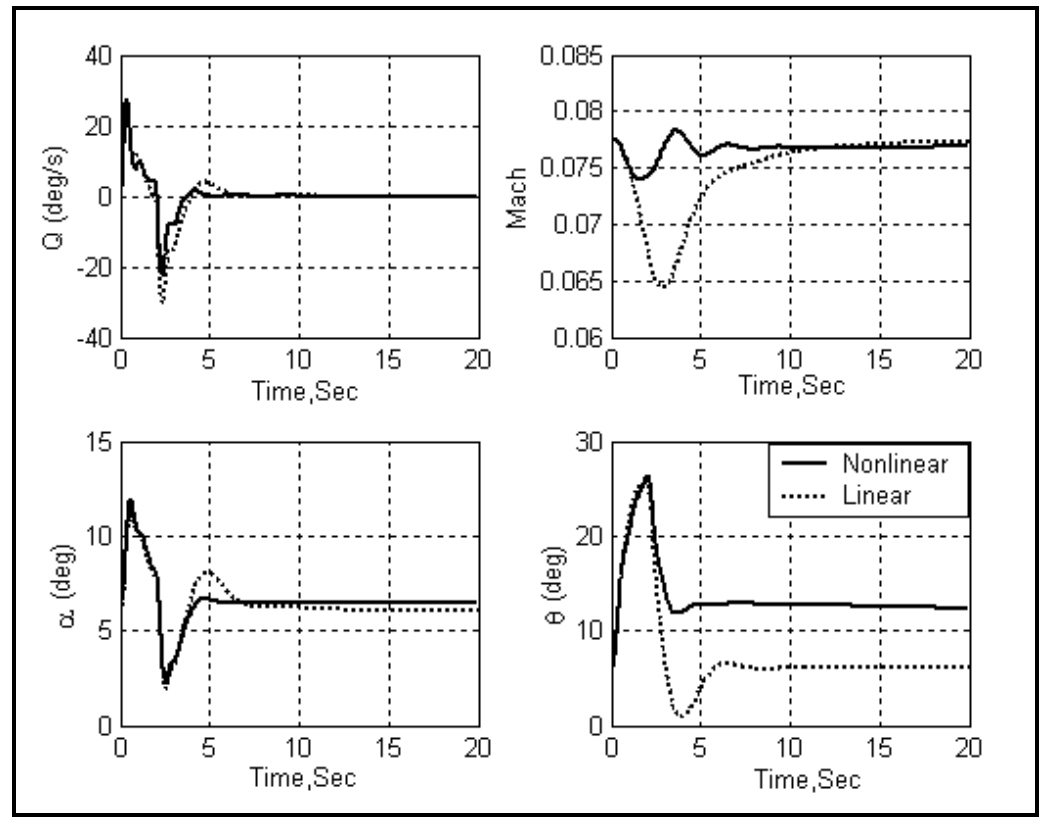

Fig. 6a Closed Loop Responses from Nonlinear and Linear Models at 26m/s

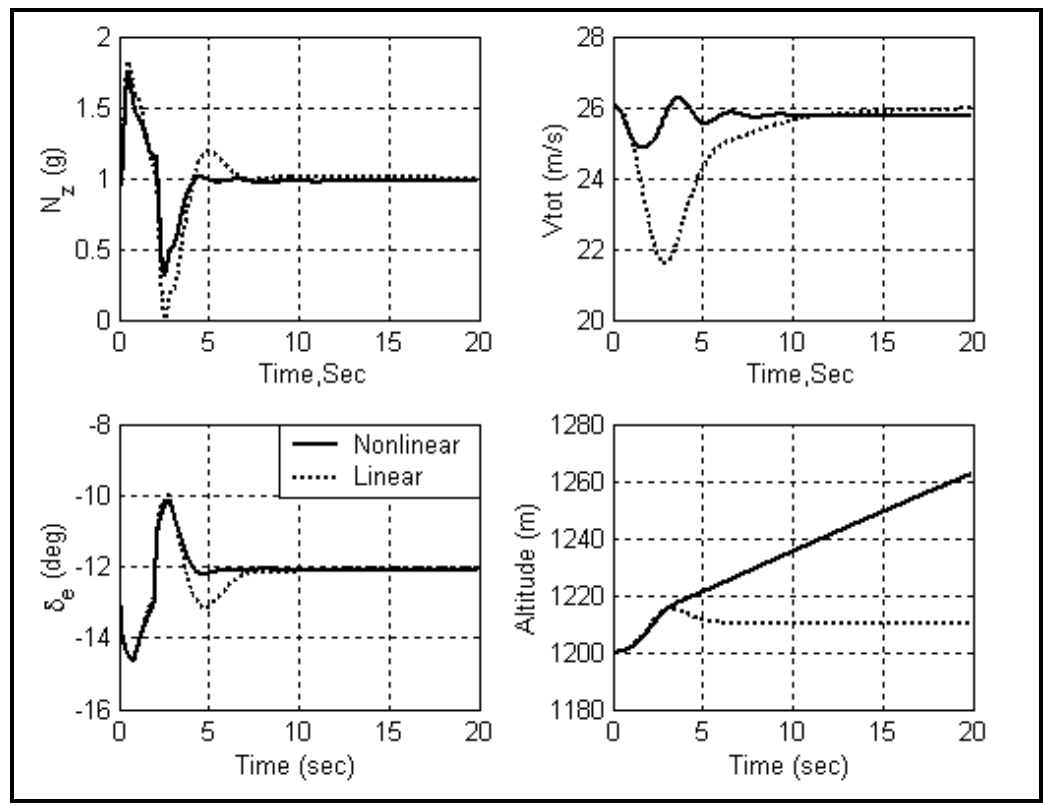

Fig. 6b Closed Loop Responses from Nonlinear and Linear Models at 26m/s 


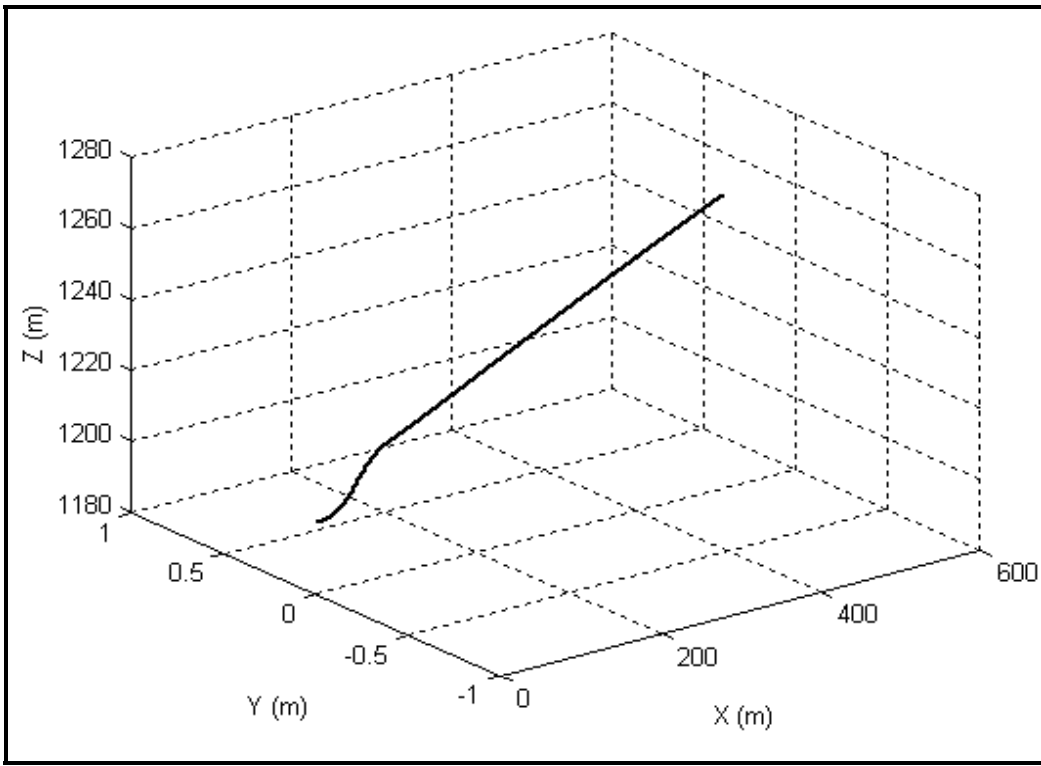

Fig. 6c Closed Loop Responses from Nonlinear and Linear Models at 26m/s

Closed loop responses simulated using linear models are also included in the same figures for the sake of comparison. At $18 \mathrm{~m} / \mathrm{s}$, responses from the nonlinear simulation are more oscillatory compared to linear simulation responses. However, at $20 \mathrm{~m} / \mathrm{s}$ and $26 \mathrm{~m} / \mathrm{s}$, the responses from nonlinear and linear simulations match well. Figures $4 c, 5 c$ and $6 c$ show the trajectory of the height variation at different flight conditions. Responses indicates that, that straight and level flight is maintained at all flight speeds, since, the gain/loss of height is very small (at $20 \mathrm{~m} / \mathrm{s}, 18 \mathrm{~m} / \mathrm{s}$ and $26 \mathrm{~m} / \mathrm{s}$, the height increases by $31 \mathrm{~m}, 9 \mathrm{~m}$ and $60 \mathrm{~m}$ respectively)

\subsubsection{Closed loop Response due to variation in Altitude}

The controller for Sarika-2 is designed based on the mathematical model derived at straight and level flight condition at an altitude of $1000 \mathrm{~m}$ above the sea level. However, the altitude at which the controller operates might be very much different from that at which it is designed. In order to analyze the degradation in performance with altitude, the aircraft is trimmed for level flight at altitudes of 1000, 1100 and $1200 \mathrm{~m}$ above sea level and its closed loop response are simulated. Figures $7 \mathrm{a}, \mathrm{b}$ and $\mathrm{c}$ shows the response of the closed loop system after trimming the aircraft at $20 \mathrm{~m} / \mathrm{s}$ for a doublet command input. 


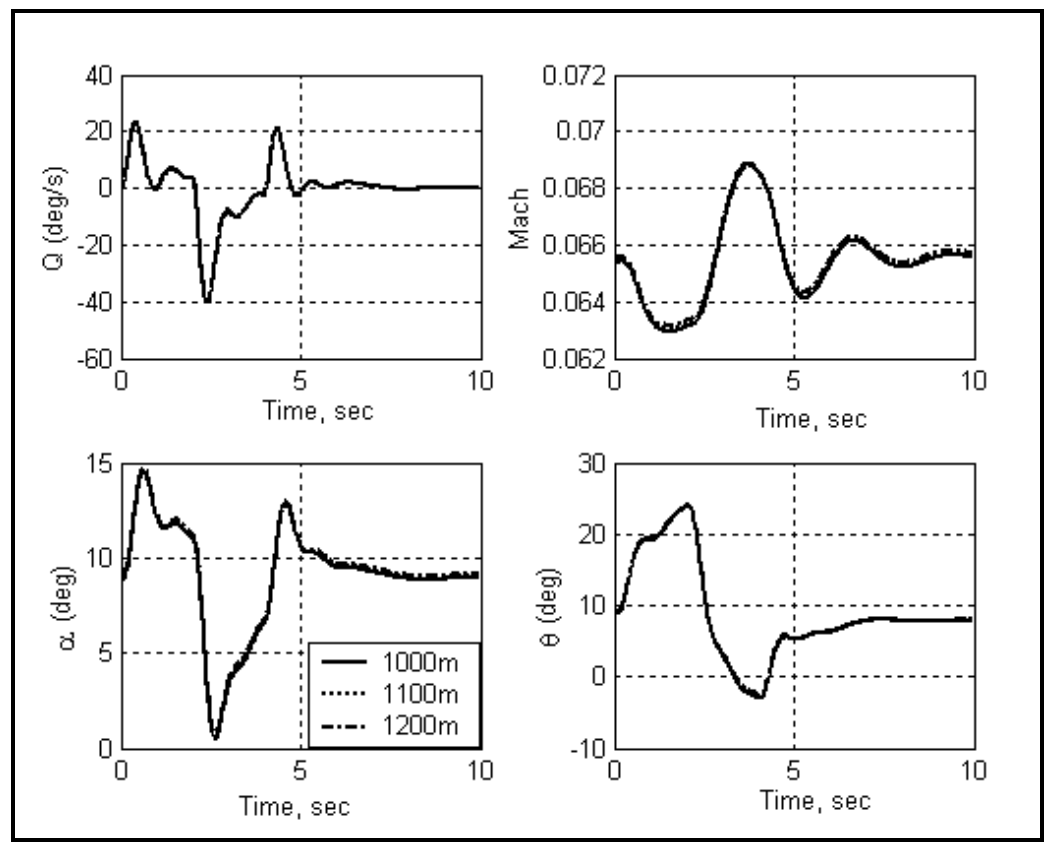

Fig. 7a Closed Loop Time Responses at different Altitude
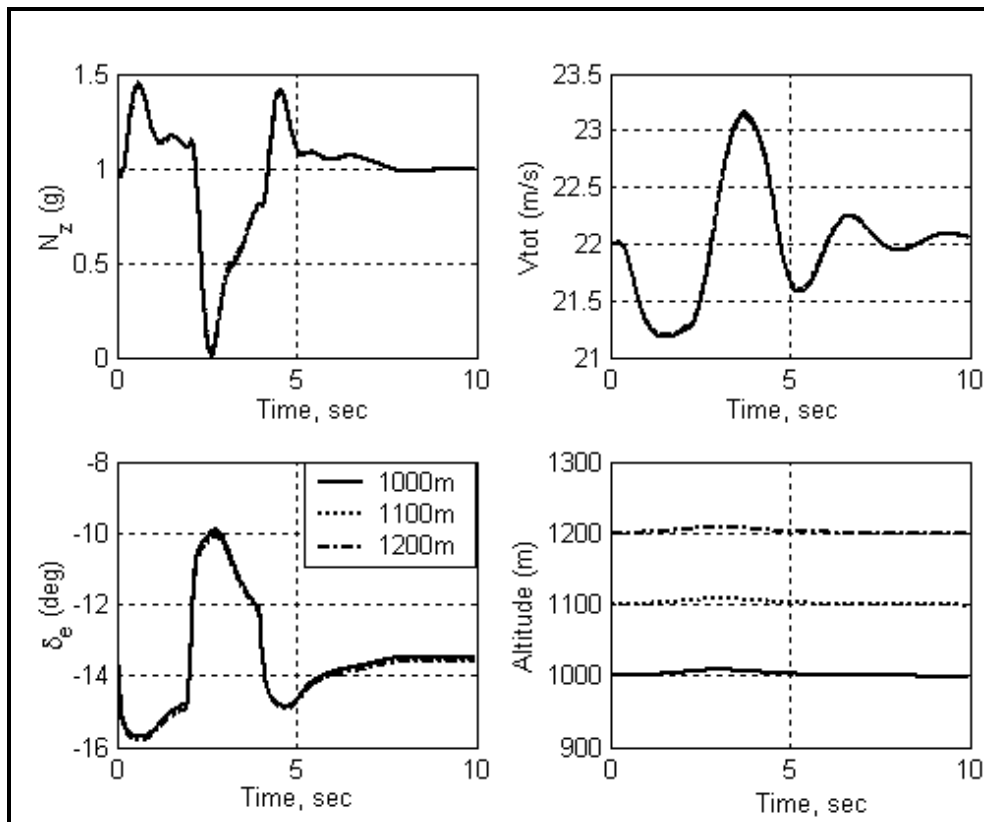

Fig. 7b Closed Loop Time Responses at different Altitude 

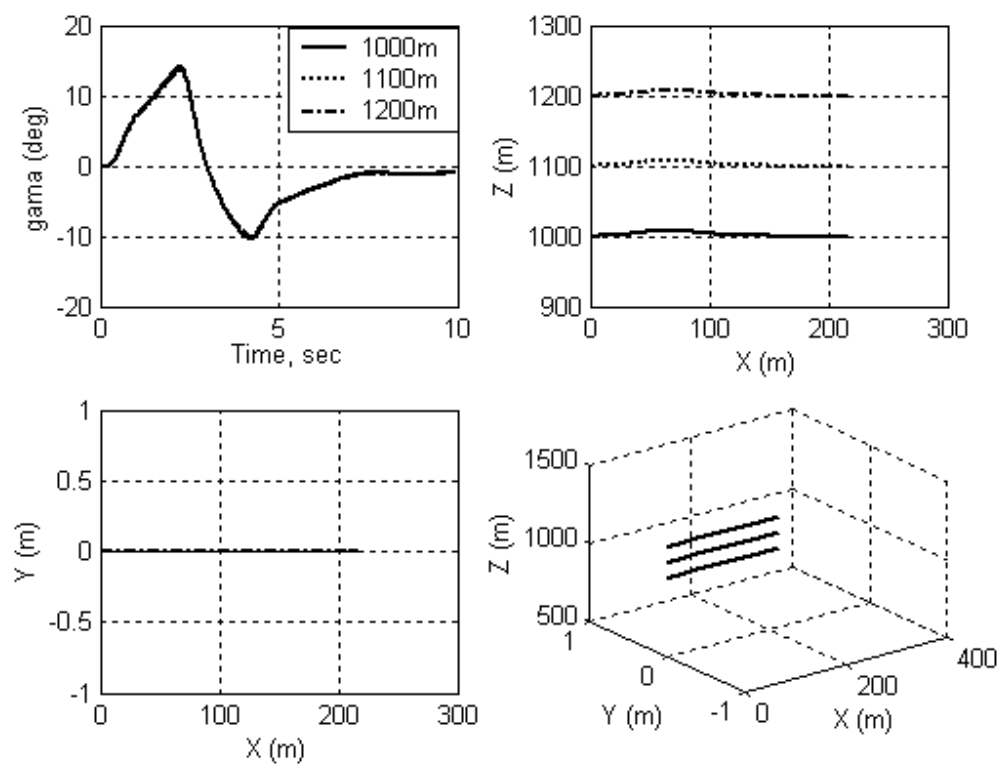

Fig. 7c Closed Loop Time Responses at different Altitude

A pulse of $-0.1 \mathrm{~ms}$ (corresponding to elevator deflection of $3.84^{\circ}$ ) and duration 2 seconds is applied at 0 seconds followed by a pulse of 0.1 milliseconds again of duration 2 seconds. However, this set of simulation does not include sensor noise and gust disturbances. Responses initiated from the trim speed of $20 \mathrm{~m} / \mathrm{s}$, shows that there is no much variation in responses due to the altitude variations. Thus, there will not be any performance degradation due to height variations in real flight. Hence, the controller is robust against the variations in altitude.

\subsection{Robust Performance Analysis with respect to real parametric uncertainty}

The affine parameter dependent uncertain model of the longitudinal dynamics is developed using the techniques mentioned before. The uncertainty levels considered in this analysis is given in the Table 3 .

\begin{tabular}{|l|l|}
\hline Stability Derivatives & Control Derivatives \\
\hline$X_{\alpha}=20 \%$ & $Z_{\delta \mathrm{e}}=20 \%$ \\
$Z_{\alpha}=25 \%$ & $M_{\delta \mathrm{e}}=15 \%$ \\
$Z_{q}=10 \%$ & \\
$M_{\alpha}=50 \%$ & \\
$M_{q}=50 \%$ & \\
\hline
\end{tabular}

Table 3. Uncertainty Levels.

The robust stability and performance of the closed-loop is analyzed using LMI based tests [7,8]. With $\mathrm{H}_{2}$ controller, (eq. 24) Quadratic stability is established on $313.4852 \%$ of the 
prescribed parameter box given in Table 3. This implies that the closed-loop system is capable of withstanding at least $\pm 156.74 \%$ of plant uncertainty, without being destabilized. Similarly, testing for the existence of a parameter dependent Lyapunov function for establishing the robust stability over a given parameter range shows that $t_{\min }=-1.143 \times 10^{-4} \mathrm{~s}$ ( $t_{\min }$ should be negative for the existence of robust stability) [7, 8]. For the same uncertainty levels, $\mu$ - upper bound is 0.2608 . Hence, largest amount of uncertainty factor $\Delta(j \omega)$ that can be tolerated without losing stability is 3.83 , which is greater than required lower bound of 1 .

\section{Conclusion}

This chapter describes design and validation of robust fixed order $\mathrm{H}_{2}$ controller for micro air vehicle named Sarika2. The controller performance is validated using linear as well as nonlinear simulation models. Simple methods to test for robust stability and performance of the closed loop system are performed using LMI based techniques. Results were proved that designed robust stability augmentation system is capable of providing the desired closed loop requirements.

\section{Reference}

Grasmeyer J. M., and Keennon M. T.,(2001) Development of the Black Widow Micro Air Vehicle, AIAA Paper 2001-0127, Published by the American Institute of Aeronautics and Astronautics, Inc.

McMicheal J.M., and Francis M.S,( 2003) Micro-Air Vehicles - Toward a New Dimension in Flight World Wide Web, http://www.darpa.mil/tto/mav/mav_auvsi.html .

Srinivasa Rao B.R., Surendranath V., and Prasanna H.R.S,(2001) Wind tunnel test results of SARIKA Airplane, Report No: AE/WT/IRR/16, Department of Aerospace Engineering, Indian Institute of .Science, Bangalore.

Bhat M. S., Meenakshi M., Govindaraju S. P., Surendranath V., and Jamadagni. H. S. (2002) Design and Development of Flight Control and Instrumentation for Micro Air Vehicle, Final Technical Report No. ARDB/MSB/TR-99-1050, Department of Aerospace Engineering, Indian Institute of Science, Bangalore.

Stoorvogel AA. (1993) The Robust $\mathrm{H}_{2}$ Control Problem: A Worst-case Design. IEEE Transactions on Automatic Control.; 38 (9): 1358- 1370

Goh K-C, Wu F. (1997) Duality and Basis Functions for Robust $\mathrm{H}_{2}$ - Performance Analysis. Automatica.; 33(11): 1949-1959.

Feron E, Apkarian P, Gahinet P (1996) Analysis and Synthesis of Robust Control Systems via Parameter-dependent Lyapunov Functions. IEEE Transactions on Automatic Control.; 41(7): 1041-1046.

Gahinet P, Nemirovski A, Laub AJ, Chilali M (1995), LMI Control Toolbox for use with MATLAB.:1.1-3.26

Green M., and Limebeer, D. J. N. (1995), Linear Robust Control, Prentice Hall, Englewood Cliffs, NJ.

Liu Y., and Anderson., B.D.O (1989), Controller Reduction: Concepts and Approaches, IEEE Transactions on Automatic Control, Vol. 34, No. 8, pp. 802-812. 
Meenakshi .M (2005), Design and Real Time Validation of Discrete Fixed Order Robust $\mathrm{H}_{2}$ Controller for Micro Air Vehicle, PhD Thesis, Dept. of Aerospace Engineering, I.I.Sc Bangalore.

Jan Roskam(1971), Flight Dynamics part 4. Roskam Aviation and Engineering Corporation Box 274 Ottawa Kansas 66067 USA:5.1-6.118.

Jan Roskam(1990), Airplane design part 6: Preliminary calculation of aerodynamic thrust and power characteristics. Roskam Aviation and Engineering Corporation Box 274 Ottawa Kansas 66067 USA: 213- 490.

Pashilkar A.A. (2003), FAST User's Manual Version 0.1, NAL PD FC 0314, Flight Mechanics \& Control Division, National Aerospace Laboratories.

Van Willigenburg. L.G and De Koning. W.L (2001), Numerical algorithms and issues concerning the discrete time optimal projection equations, European Journal of Control, Vol. 6, No. 1, pp. 93-110,. 


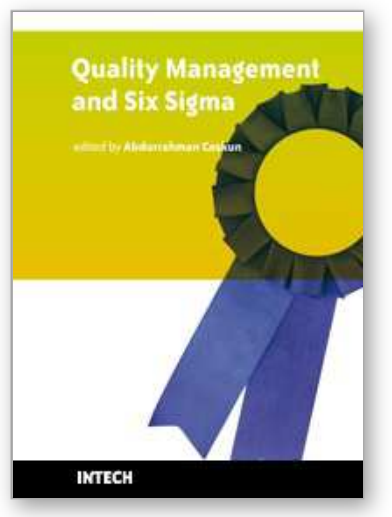

\author{
Quality Management and Six Sigma \\ Edited by Abdurrahman Coskun
}

ISBN 978-953-307-130-5

Hard cover, 276 pages

Publisher Sciyo

Published online 16, August, 2010

Published in print edition August, 2010

If you do not measure, you do not know, and if you do not know, you cannot manage. Modern Quality Management and Six Sigma shows us how to measure and, consequently, how to manage the companies in business and industries. Six Sigma provides principles and tools that can be applied to any process as a means used to measure defects and/or error rates. In the new millennium thousands of people work in various companies that use Modern Quality Management and Six Sigma to reduce the cost of products and eliminate the defects. This book provides the necessary guidance for selecting, performing and evaluating various procedures of Quality Management and particularly Six Sigma. In the book you will see how to use data, i.e. plot, interpret and validate it for Six Sigma projects in business, industry and even in medical laboratories.

\title{
How to reference
}

In order to correctly reference this scholarly work, feel free to copy and paste the following:

Meenakshi M (2010). Longitudinal Robust Stability Augmentation for Micro Air Vehicle - Design and Validation, Quality Management and Six Sigma, Abdurrahman Coskun (Ed.), ISBN: 978-953-307-130-5, InTech, Available from: http://www.intechopen.com/books/quality-management-and-six-sigma/longitudinal-robust-stabilityaugmentation-for-micro-air-vehicle-design-and-validation

\section{INTECH}

open science | open minds

\section{InTech Europe}

University Campus STeP Ri

Slavka Krautzeka 83/A

51000 Rijeka, Croatia

Phone: +385 (51) 770447

Fax: +385 (51) 686166

www.intechopen.com

\section{InTech China}

Unit 405, Office Block, Hotel Equatorial Shanghai

No.65, Yan An Road (West), Shanghai, 200040, China 中国上海市延安西路65号上海国际贵都大饭店办公楼 405 单元

Phone: +86-21-62489820

Fax: +86-21-62489821 
(C) 2010 The Author(s). Licensee IntechOpen. This chapter is distributed under the terms of the Creative Commons Attribution-NonCommercialShareAlike-3.0 License, which permits use, distribution and reproduction for non-commercial purposes, provided the original is properly cited and derivative works building on this content are distributed under the same license. 